\title{
Comparing Per Capita Output Internationally: Has The United States Been Overtaken?
}

\author{
JAI-HOON YANG
}

㰏

N 1950 the United States was generally recognized as having the highest per capita output in the world. Using exchange rates to convert foreign output into dollars, the level of U.S. per capita output in 1950 was more than 50 percent higher than that of any other industrialized country. ${ }^{1}$ During the next two decades the conventional exchange rate-based measure of comparison indicated that these industrialized countries markedly narrowed the U.S. lead. By 1970 U.S. per capita output was still more than 15 percent higher than the next highest industrialized country, Sweden.

By 1974, however, that same conventional measure indicated that Sweden and Switzerland had overtaken the United States. Reportedly, Canada, Denmark and West Gemany have joined the club. ${ }^{2}$ Citing these developments, one critic of the U.S. economic system speculated that "the lack of government plan-

${ }^{1}$ The concern here is with the relative per capita levels of actual output of goods and services produced (such as per capita gross national product or gross domestic product as conventionally measured in accordance with the prevailing United Nation's System of National Accounts ) and not with the elusive and speculative meastres of relative levels of economic welfare. The primary reason for focusing on a measure of production, such as per capita output, rather than on a measure of welfare, such as consumption per capita adjusted for length and conditions of work, is that in most studies and popular discussions of international comparisons, measures of per capita output have been used. For a discussion of reasons why measures of production, rather than of welfare, are compared, see Milton Gilbert and Irving B. Kravis, An International Comparison of $\mathrm{Na}$ tional Products and the Purchasing Power of Currencies (Paris: Organization for European Economic Cooperation (OEEC) -1954), pp. 72-76. For a discussion of the distinction between a measure of welfare and a measure of output, see Edward F. Denison, "Welfare Measurement and the GNP", Survey of Current Business (January 1971), pp. 13-16, 39.

"West Germany was reported to have become "just a bit richer" than the U.S. on a per capita basis on June $24,1973$. See J. W. Anderson, "The Relative Wealth of Nations," Washington Post, 2 July 1973. Denmark's leap forward was reported in early 1977 . See Lester C. Thurow, "The Myth of the American Economy," Newsweek (February 14, 1977), p. 11. These reports are based on a temporary (as short as a day) dip in the value of the dollar. Based on an annual or even on a quarterly average basis, Denmark and West Germany have yet to pass the United States, even in terms of the conventional measure. Canada's entry into this exclusive club was reported recently in "U.S. Slips to 4 th in National Income," Washington Post, 13 May 1978. ning, worker participation, and social spending may in fact be at the heart of our poor performance in recent decades."3

There is good reason to question the conclusion about the comparative levels of per capita output based on the conventional (exchange rate-based) measure. Specifically, the method of using exchange rates to convert output of different countries into a common currency, such as the U.S. dollar, has several serious drawbacks. First, actual per capita out put of goods and services in different countries does not necessarily change every time exchange rates between the countries change, although the conventional measure of comparison would indicate such a change. Second, the exchange rate between currencies serves to equalize, at best, the prices of goods traded between countries. However, total output in each country also consists of goods and services which are not traded but are consumed domestically. Price differences in these non-traded goods are not necesarily captured in the exchange rate. To the extent the exchange rate does not reflect such a difference in the prices of non-traded goods, any comparison based on the conventional measure would be dis torted. In addition, the prevaiting exchange rate may not even equalize the prices of goods traded internationally for a variety of reasons, including government interventions in the markets for foreign exchange.

To overcome these shortcomings of the exchange rate-based measure, ecomomists have developed an alternate measure based on the relative purchasing power of different currencies over both traded and non-traded goods. This alternate measure of international comparison indicates that the U.S. lead in per capita output in the earlier period (1950 through 1970) was generally much narrower than that indicated by the conventional measure. Also, these estimates indicate that the U.S. lead has yet to be overtaken.

3See Thurow, "The Myth," p. 11. 


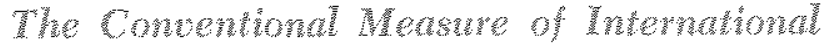

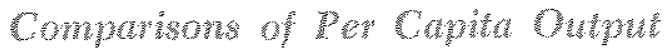

The conventional measure of international comparisons using exchange rates between two countries, say, Germany and the United States, is quite simple. First, the per capita German output in Deutsche marks (DM) would be converted to dollars by the prevailing exchange rate. The resulting per capita German output in dollars would be divided by the per capita U.S. output, also measured in dollars. The resulting quotient, expressed in percentage form, is the conventional measure of the relative level of per capita output between Germany and the United States. For example, suppose that per capita German output in a given year is DM4,000 while U.S. per capita output is $\$ 2,000$. Assume that the exchange rate is DM $4 / \$ 1.000^{4}$ To derive the conventional measure of international comparison, the per capita German output wotld be converted to dollars (DM4000 $\div$ DM $4 / \$ 1=\$ 1000$ ) and then expressed as a percent of U.S. per capita output $(\$ 1000 / \$ 2000=.50$, or 50 percent $)$. For the sake of illustration, if the exchange rate in this example changes to DM $2 / \$ 1.00$ (the dollar depreciates), the conventional measure becomes 100 percent. In other words, per capita output in Germany would be estimated to be equal to that of the United States.

This conventional measure of international comparisons is a unique number for given estimates of per capita output of any two countries (denominated in their respective national ctrrencies) and a given exchange rate. Also, the conventional measure is easy to construct. These attractive features explain why the conventional measure is regularly published and widely quoted. ${ }^{5}$ However, this procedure is fraught with conceptual difficulties. So much so that since the early 1950 s, there have been concerted attempts to construct more appropriate measures. ${ }^{6}$ The im-

${ }^{4} \mathrm{DM} 4 / \$ 1.00$ denotes that 4 units of the German currency (Deutsche mark) can be exchanged for one U.S. dollar.

5Statistical Yearbook, 1976 (New York: United Nations, 1977), pp. 686-88; The World Bank Atlas: Population, Per Capita Product, and Growth Rates (World Bank, 1976); "East vs. West: Who's Richer - and Why," The Morgan Guaranty Survey (February 1978), pp. 6-9; and "A Special Report Socialism: Trials and Errors," Time (March 13, 1978), especially pp. $26-27$.

GFor a pioneering study of international comparisons based on an extensive collaboration with the statistical agencies of the countries involved, see Cilbert and Kravis, An International Comparison of National Products. For a follow-up study with ar expanded coverage, see Milton Gilbert and associates, Comparative National Products and Price Levels; a Study of Western Eturope and the United States (Paris: OEEC, 1958). For a recent study, see Irving B. Kravis, Zoltan Kenessey. Alan Heston and Robert Summers, A System of Intemational Comparisons of Gross Product and Purchasing Power (Balti- portant point to note for now is that the allegation that the United States has lost its lead in per capita output in the 1970s has been based exclusively on the conventional measure of international comparisons.

\section{The Nane of the Difrethy

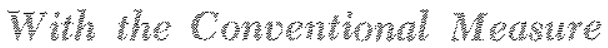

Intemational comparisons of per capita output must be based, in principle, on a comparison of the quantities of both internationally traded goods (such as radios) and non-traded goods (such as haircuts) produced in different countries. ${ }^{\top}$ The basic difficulty with the conventional measure, which uses prevailing exchange rates, is that this measure is known to be valid only when (a) the relative prices of traded and non-traded goods are identical between the countries (a haircut costs the same amount in terms of radios in both countries), and (b) the prevailing exchange rate is such that the prices of traded goods are equalized (an American-made radio costs just as much as one of similar quality made in Germany). These conditions, especially the one calling for identical price structures (relative prices) in each country, are unlikely to be met. Therefore, there can be no presumption that the procedure underlying the conventional measure would yield a valid measure of comparison.

To clarify this point, consider the example given in Table I. There are two hypothetical countries, Alpha and Beta. Prices in Alpha are denominated in pounds, denoted by $\&$. Beta's prices are denominated in dollars, denoted by $\$$. Country Beta is assumed to produce greater amounts per capita of both traded goods, such as radios, and non-traded goods, such as haircuts. Country Alpha produces $2 / 3$ as many radios per capita as country Beta and $1 / 3$ as many haircuts per capita. If we compared only the traded goods, Alpha's output would be $2 / 3$ or 66.7 percent of Beta's; on the basis of non-traded goods, Alpha's output would be $1 / 3$ or 33.3 percent of Beta's output. However, the task of comparing per capita output internationally is to express country Alpha's

more and London: the Johns Hopkins University Press for the Work Bank, 1975). The first two studies are based on the comparison of GNP and its components. The study by Kravis, et al. deals with the GDP and its components.

FNonutraded goods, of course, include government provision of goods and services which are not priced in the market place. Valuation and comparison of such government output present difficult conceptual and measurement problems which are ignored in this paper. For a recent attempt to deal with the problem of valuing government ontput, see Keith Leffler, "Government Output and National Income Estimates: The Effect on International Comparison (fortheoming in Carnegie-Rochester Conference Series, 9, 1978). 


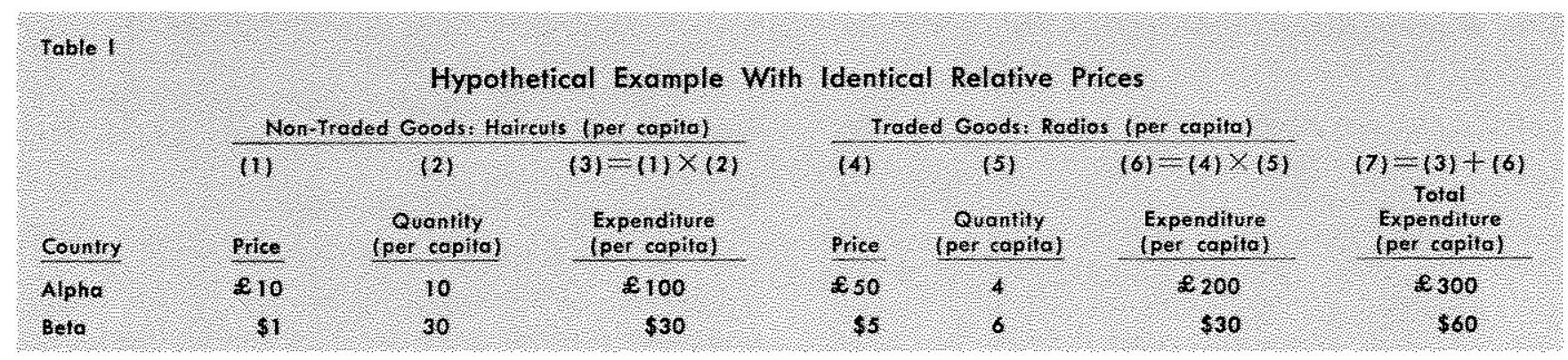

total output per capita as a percentage of country Beta's total output per capita. Therefore, a valid measure of comparison would fall somewhere within the upper and lower limits of the ratios (expressed in percentages) of the quantities of each good and service produced in one country to those of another. For this example, a valid measure of comparison must place the total per capita output of Alpha somewhere between 33.3 percent and 66.7 percent of that of the total per capita output of Beta. Conversely, any measure that does not fall within these limits is not a valid measure.

In Table I, the relative price of radios and haircuts is assumed to be identical in both countries, that is, radios cost 5 times as much as haircuts in both countries ( $£ 50 / 210$ and $\$ 5 / \$ 1$ ). The average level of prices in Alpha (in $\mathscr{E}$ ) is assumed to be 10 times higher than that in Beta (in $\$$ ). If the exchange rate is $£ 10 / \$ 1.00$, as is likely under free trade, the underlying condition that justifies the use of the conventional measure is met. The relative level of per capita output of Alpha would be computed by first dividing the aggregate value of its per capita output ( $£ 300$ ) by the exchange rate and then expressing the resulting figure of $\$ 30(\& 300 \div \& 10 / \$ 1.00)$ as a percent age of the aggregate value of Beta's per capita output (\$60). In this instance, the resulting conventional measure is 50 percent which falls within the limits required for a valid measure.

However, there is no presumption that the procedure underlying the conventional measure would yield a valid measure of comparison when relative prices differ between countries. To analyze a more likely case where relative prices of traded and nontraded goods are different between countries, consider the example given in Table II (which is identical to Table I except that the price of radios in Alpha is now $\& 15$ rather than $\& 50$ ). Relative prices in the two countries are no longer identical. Radios cost 5 times as much as haircuts in Beta whereas radios cost only $1^{1 / 2}$ times as much as haircuts in Alpha.

Since the prices of traded goods are assumed to be equalized internationally through adjustment in the exchange rate, the equilibrium exchange rate would be $23 / \$ 1.00$ for this example. The conventional measure for comparing per capita output in this instance would be 88.9 percent $[(£ 160 \div 23 / \$ 1.00)$ $\div(\$ 60)=.889]$. Thus, the conventional measure is immediately seen to be an invalid measure for comparing per capita output since it is even higher than the highest of the relative quantities in the example (66.7 percent for radios, the traded good).

As these examples demonstrate, only under the twin assumptions of (a) identical domestic price structures (relative prices) across countries and (b) a market determined exchange rate which equalizes the prices of traded goods would the procedure underlying the conventional measure yield a valid measure for comparing per capita ontput between countries. These special assumptions are not generally met for a variety of reasons. Inter-country productivity differentials across commodity groups (such as traded vs. non-traded goods) would result in different domestic price structures. Also, government interference,

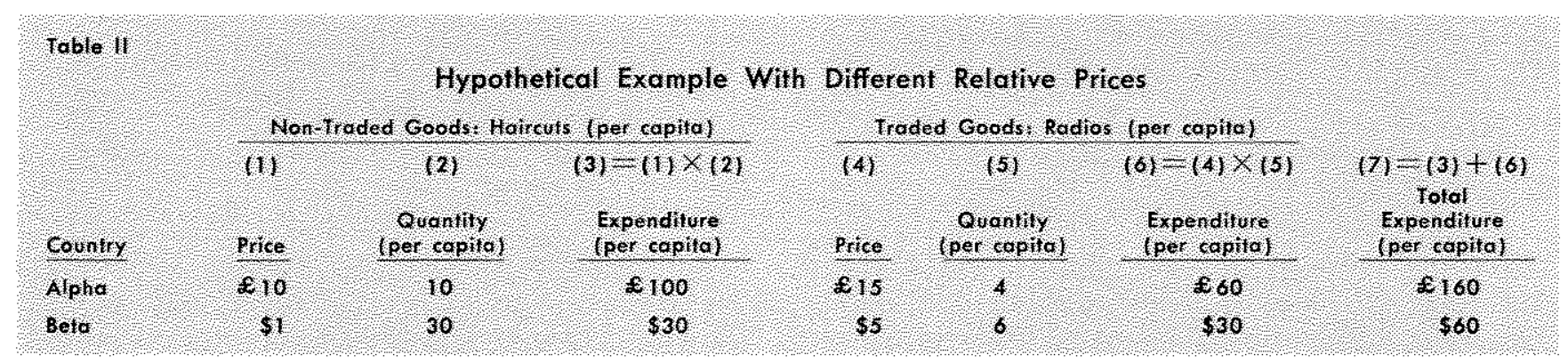

Page 10 
through such devices as exchange controls and import quotas, distorts the exchange rate such that it may not equalize the prices of traded goods between the two countries.

Even where the exchange rate is allowed to be determined freely in the foreign exchange market, one is not likely to observe equal prices for traded goods. Some prominent reasons given for this are the differences in (a) the cost of transportation, processing and distribution, both between and within countries, (b) tax structures (indirect vs. direct taxes), and (c) selective subsidies on certain classes of commodities. ${ }^{8}$

Hence, the conventional measure based on the exchange rate is not necessarily a valid measure for comparing per capita output between countries. The point to note is that the conclusions regarding the comparative levels of per capita output since 1950 and the allegations about the United States falling behind in the 1970s are founded on no more substantive basis than the conventional measure of international comparison discussed and illustrated in this section.

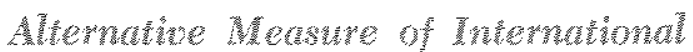 \\ Comprisons Bused on Purchasing \\ Pouser Partick}

A generally valid measure for comparing per capita output between countries can be constructed by using what is known as the purchasing power parity (PPP) of currencies. PPP is defined as the ratio of the number of units of one country's currency (say Deutsche mark) to the number of units of another country's currency (say the U.S. dollar) which are required to purchase the same bundle of both traded and nontraded goods. To estimate PPP, the total per capita output of a given country is priced first by the prices prevailing in the given country and then by the other country's prices. An estimate of PPP is obtained by the ratio of the resulting market values of the total per capita output which has been priced. An alternative estimate of PPP may be obtained by pricing the total per capita output of the other country. Examples of PPP calculations are shown in Table III.

For the example in Table I where the price structures are identical, PPP is unique (at $£ 10 / \$ 1.00$ )

sFor a discussion of the limitations of the conventional measure, see Gilbert and Kravis, An International Comparison of $\mathrm{Na}$ tional Products, pp. 14-17. Also see Paul A. David, "Just How Misleading Are Official Exchange Rate Conversions?" Economic Joumal (September 1972), pp. 979-90, Robin Barlow, "A Test of Alternative Methods of Making CNP Comparisons," Economic Joumal (September 1977), pp. 450-59.

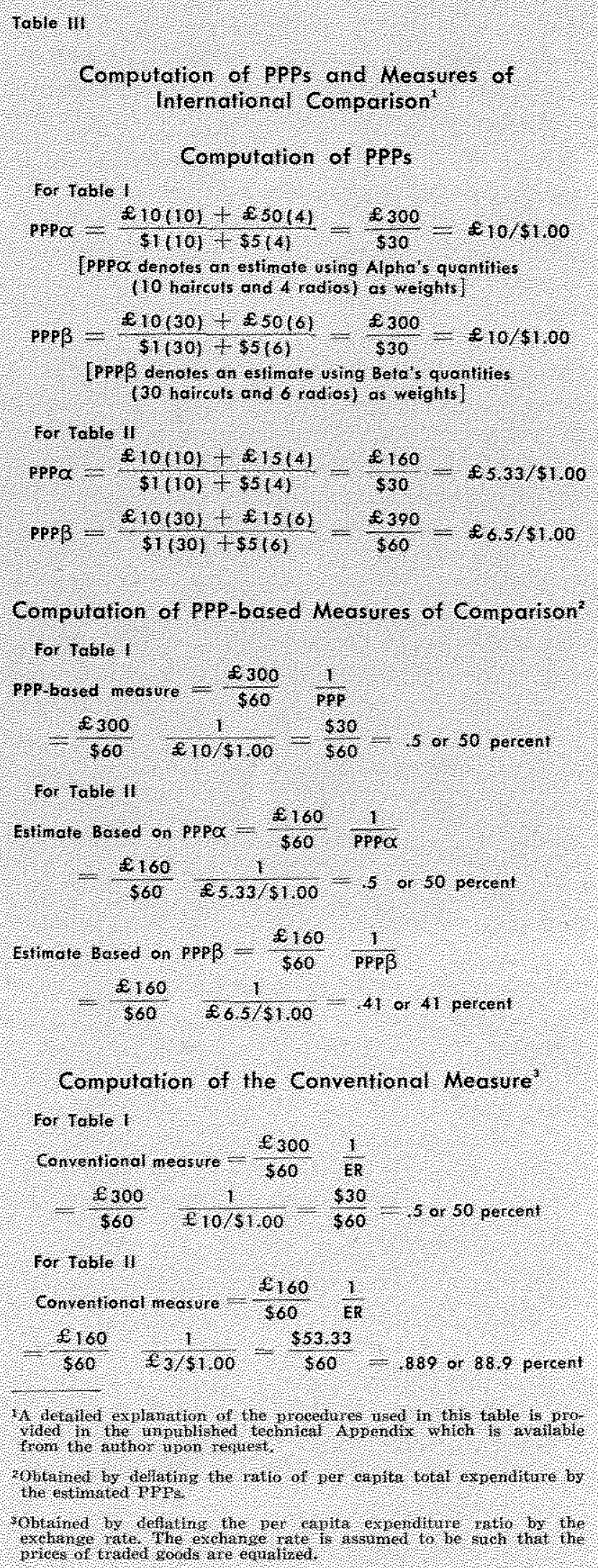

Fo. Table 11

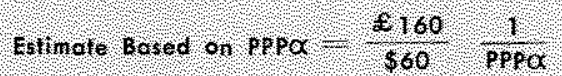$$
\begin{gathered}
0.160 \\
560
\end{gathered}
$$

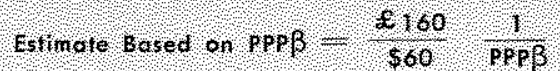

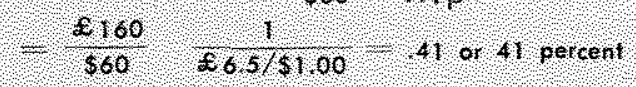

\section{Computation of the Conventional Measure?}

tor roble

$$
\begin{aligned}
& \text { Gonventional neasure } \frac{4300}{560} \text { t }
\end{aligned}
$$

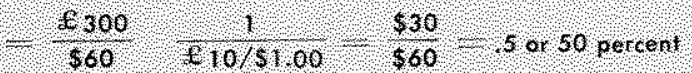

For Toble ol

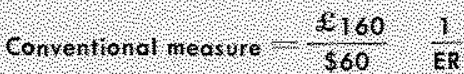

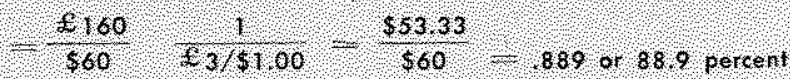

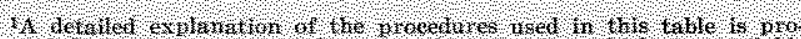

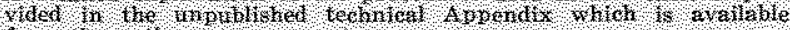

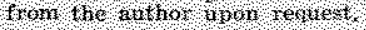

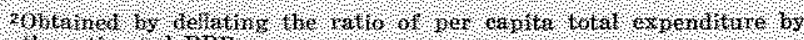
the etthited PPTS

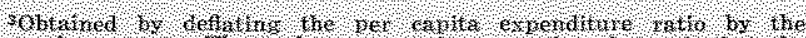
exphange rate the exelongse rate is assumed to be ach that the price of thatdes 8000 s ate edvalfined 
and would be equal to the exchange rate if the exchange rate is such that the prices of traded goods are equalized. ${ }^{9}$ When the price structures are different as in Table II, however, the PPP is not, in general, equal to the exchange rate. ${ }^{10}$

Hence, the alternative measure for comparing per capita output based on PPP is not in general equal to the conventional measure based on the exchange rate. To illustrate the difference in the exchange rate-based conventional and the PPP-based alternative measures of international comparisons of per capita output, refer to Table III. Computations reported in Table III illustrate that the PPP-based measures are valid for comparison in the sense that they (being 41 percent and 50 percent) lie between the upper and lower limits ( 66.7 percent and 33.3 percent) of relative quantities of traded and non-traded goods. As noted above, the conventional measure derived by the use of the exchange rate, on the other hand, is inappropriate in that it, being 88.9 percent, lies outside of these limits. In general, the use of PPP first to convert the per capita output of a given country into common currencies and then to express it relative to the per capita output of the base country yields without exception a valid measure for comparing the per capita output of the two countries."

-For a discussion of the relationship between the exchange rate and the purchasing power parities (PPP) of currencies, see Bela Balassa, "The Purchasing-Fower Parity Doctrine: A Reappraisal," Journal of Political Economy (December 1964), pp. 584-96. When PPP is equal to the exchange rate, the absolute version of the purchasing power parity doctrine is said to hotc. The doctrine posits a relationship between the rate of exchange between two currencies and the purchasing power of currencies over both traded and non-traded goods in two countries. The absolute version links the level of exchange rates one-for-one to the purchasing power parities, whereas the relative version of the doctrine relates the required adjustment in the exchange rate (from the posited base-period equilibrium exchange rate) to the relative changes in the general price levels. There are no theoretical reasons for either one of these versions of the doctrine to hold, unless the relative price structures either remain unchanged of become identical. See Balassa, "Doctrine," pp. 584-87.

${ }^{10}$ Computations given in Table III show that PPP is not equal to the exchange rate (assumed to be $\mathcal{E} 3 / \$ 1,00$ ) but ranges between $£ 5.33 / \$ 1.00$ and $x^{2} 6.5 / \$ 1.00$. This refiects the fact that, given the lower relative price of traded goods in Alpha, the comparative purchasing power in Alpha's curreney over both traded and non-traded goods is lower than that indicated by the exchange rate which takes into account only the prices of traded goods. Thus, whereas the exchange rate indicates $\& 3$ is equivalent in perrehasing power (over the traded good) to $\$ 1.00$, the PPP indicates that $\& 5.33$ (or $\mathfrak{E} 6.5)$ is equivalent to $\$ 1.00$ in buying power over both the traded and non-traded yoods. Firther, the use of own quantity weights, rather than the quantity weights of Beta, results in a larger estimate of the purchasing power of $f$ (that is, a smaller estimate of PPP) because relatively cheaner traded yoods get a greater weight in the estimation of PPP. When PPPs are not unique, geometric averages of the different estimates of PPP are often used.

11 A more general substantiation of these points, made so far

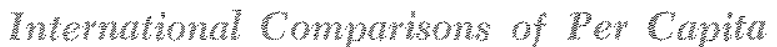

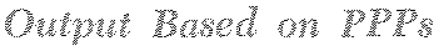

The alternative PPP-based measures for comparing per capita output have not been widely used in the past, however, primarily because of the relatively high cost of constructing them. Conventional meas. ures can easily be constructed with data routinely available in regularly published statistical releases. The data collection and processing requirements for the construction of the PPP-based measures are staggering. Such measures require, in principle, price and quantity information on each individual good and service produced in different countries. ${ }^{12}$ In addition to the cost of data collection, the existence of commodities which are unique or not identical in quality (such as a Rolls-Royce vs. a Volkswagen) poses both conceptual and measurement problems. ${ }^{13}$

The high cost of using the PPP method explains why the estimates based on this method are available for only a selected number of countries and only for selected periods. ${ }^{14}$ Essentially, PPP-based estimates are available for 1950, 1960 and 1970 . Table IV lists PPP-based estimates relative to the United States for a sample of countries for which data are available for some years through 1970 (with the exception of Switz-

with the aid of simple examples, is provided in an unpublished technical Appendix which is avalable from the author upon request. It is shown in that Appendix that the basic difficulty with the conventional measture is that the procedure underlying its computation does not yield, in general, a measure called a quantity index (that is, a weighted average of the quantity ratios or relatives of each distinct group of commodities). It is a quantity index which must be constructed in order to make an international comparison of per capita output of goods and services. The procedure underlying the conventional measure is shown to be equivalent to detating the ratio of per capita expenditures (expressed in different currency units) by the prevailing exchange rate. An alternative approach by which the per cavita expenditure ratio is deflated by an estimate of the purchasing power parity (PPP) of currencies is shown to yield - without exception - a quantify index. Hence, the alternative, PPP-based estimates of comparative levels of per capita output must be used to make a valid comparison of per capita output across countries.

12 In practice, however, price and quantity data on aggregate categories - such as men's clothing, passenger cars, furniture, and physicians services - are constructed by decomposing the more readily available expenditure data, using primarily the price data on selected components of each category, for example, dress shirts and business suits for the men's clothing category. The most recent U.N. study uses for exaruple, 153 such expenditure categories. See Kravis, et al., A System of International Compartisons, p. 171.

${ }^{13}$ Fo: a discussion of the statistical procedures used to deal with these problems, see Gilbert and Kravis, An International Comparison of National Products, pp. 79-91; Kravis, et al, A System of Intemational Comparisons, pp. 31-34.

14 For an exhaustive list of the countries and the time periods for which the PPP-based measures are available, see Irving B. Kravis, "A Survey of International Comparisons of Productivity," Economic Journal (March 1976), p. I9. 


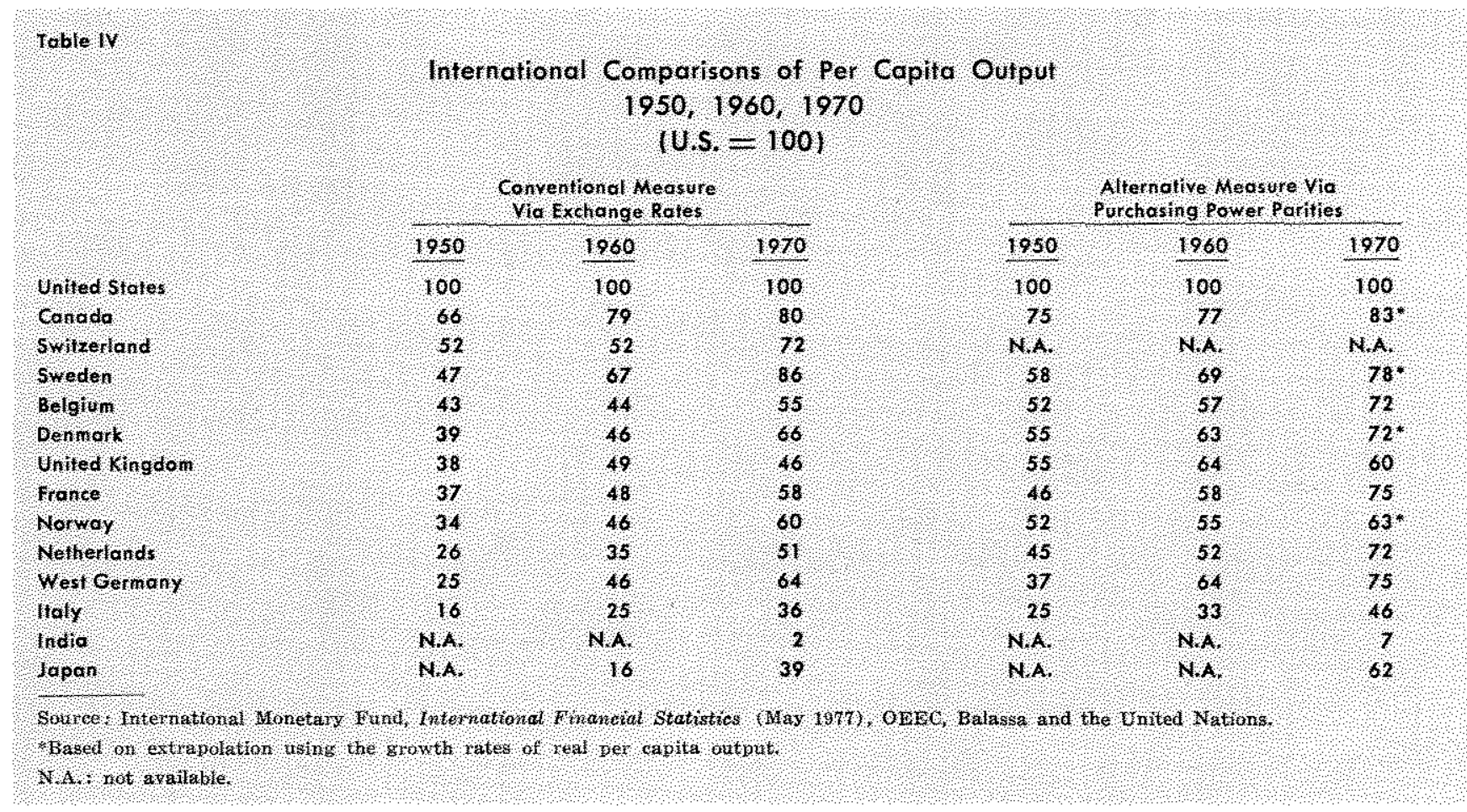

erland). Compared to the conventional measure given in the same table, the PPP-based measure indicates that the U.S, lead in per capita output was not as great in 1950 . For example, the U.S. per capita output was a trifle more than twice that of the Netherlands according to the PPP-based measure, rather than the nearly four fold lead indicated by the exchange rate-based measure. Both measures indicate that the gap has narrowed over the 20-year period and that the U.S. lead has yet to be overtaken through 1970.15 The alternative (PPP-based) measure indicates, however, that the narrowing of the gap in most cases has not been as dramatic as indicated by the conventional measure. ${ }^{16}$

15For those countries for which the PPP-based measure was available for 1960 and earlier but not for 1970 , the 1970 estimate was obtained by extrapolating the 1960 measure by the differential growth rates of real per capita output between the given country and the United States.

16Table IV also indicates that the conventional measure based on the exchange rate tends to be lower than the PPP-based estimate over this period. However, given the varying degrees of intervention in the foreign exchange markets and changes in the role a tational currency (such as the U.S. dollar) plays as international means of payment and store of value, there is no necessity for the conventional measure to be systenatically lower than the PPP-based measture, especially for countries with relatively similar price structures and productivity. The fundamental point to note is that the PPP.based measure is a valid meastre withou exception and that the conventional measure can be on either side of the PPP-based measure, depending upon the particular historical circumstances that happen to prevail. Even the direction of bias in the conventional measure camot be assessed $a$
In order to assess the allegation, based on the conventional measure, that the United States has lost its lead in per capita output in the 1970s, we proceed as follows. For each selected country the latest available PPP-based estimate of per capita output is projected forward in time by using the various countries' actual growth rate in per capita output. The PPP-based estimate for the United States is similarly projected. Comparison of the projections for each country, expressed as percentages of the projection for the United States, is then made.

As an illustration of the method, the PPP-based estimate for West Germany in 1970 can be used. The PPP-based estimate of per capita output for Germany in that year is 75 percent of that of the United States. To derive the PPP-based estimate for 1976, for example, the German per capita output for 1970 was calculated by first multiplying the 1970 U.S. per capita output by the PPR-based measure of comparison for

prori but must be determined on a case-by-case and comtryby-country basis, that is, only after the conventional measure is compared to the PPP-based measmre. The observed tendency of the conventional neasure to be lower than the PPP-based estimate over this period has been explained in terms of greater inter-country productivity differential in the tanded-goods sector (such as manufacturing and agriculture) than in the non-traded goods sector (such as personal services and govermment). The presumption has been that there is a greater opportumity for technological innovations in the traded goods sector. For details, see Balassa, "Doctrine." 


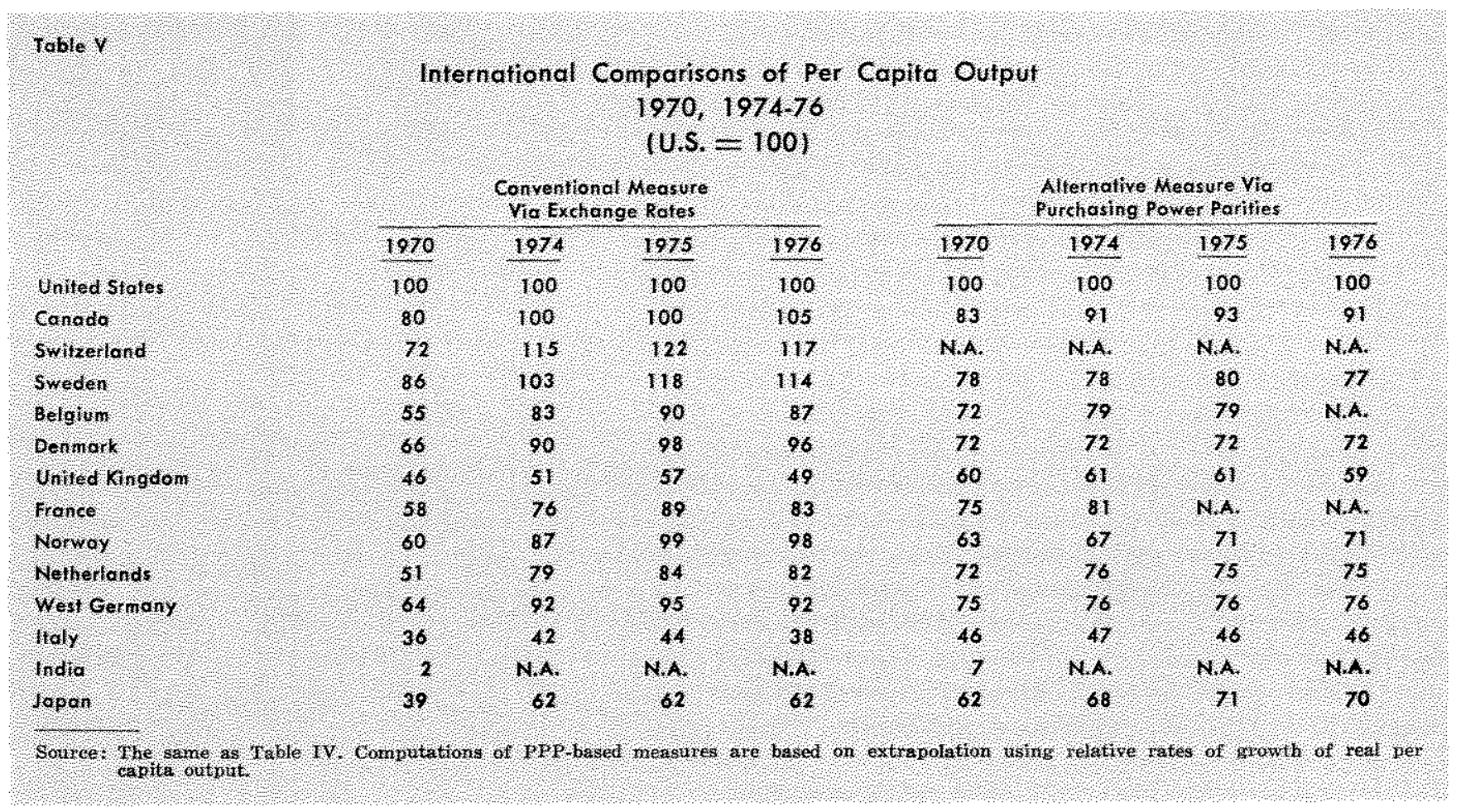

Germany for 1970. The German per capita output in 1970 (in 1970 U.S. prices) is $\$ 3596$ ( 75 percent of $\$ 4795$ for the U.S. in 1970 ). This 1970 German per capita output was extrapolated to 1976 by using the average growth rate ( 2.3 percent per year) of the German real per capita output over the 1970-1976 period. The resulting figure of $\$ 4125$ was 76 percent of the 1976 per capita U.S. output (in 1970 U.S. prices). Consequently, the estimated PPP-based measure in 1976 was 76 percent for West Germany, ${ }^{17}$

Table $V$ provides comparisons based on these extrapolated estimates and on the conventional measure

17This method admittedly involves the assumption that the price structure in one country has not changed relative to that of the other combtry over the extrapolation period. It may appear that the objection raised to the use of the exchange rate, that it assumes identical price structures across countries, is applicable to this method of extrapolating the PPP-based estimate. However, this extrapolation method is superior for the purpose of comparing the levels of per capita output since the use of the PPP provides a correct gauge of the comparative levels of per capita output for the initial period. The use of the exchange rate would not lead to a correct measure of relative levels of per capita output at any time over the entire period of comparison, as long as the price structures are not identical. The basic reasons of course, are that the PPP-based method, unlike the exchange rate method, is not distorted by the different degrees of intervention in the exchange market and that the method allows for the differences in the prices of both traded and non-traded goods. The available evidence indicates that this extrapolation method is superior to the exchange rate-based method. See the discussion below and Kravis, et al, A System of International Comparisons, pp, 8-9, especially footnote 13 . for 1970 , and for 1974 through $1976 .^{18}$ The numbers are in index form, with the United States scaled at 100. Therefore, if a number exceeds 100 , it sustains the claim that the United States has been overtaken by that country.

The conventional measure indicates that some countries have overtaken the United States in the 1970s. Per capita output in Switzerland, for example, was 72 percent of the United States in 1970. By 1974, Swiss per capita output exceeded that of the United States, standing at 115 percent of that of the United States. Such a reversal in the comparative position is hard to accept, however, because of what it implies about the relative growth rates of per capita output over the 1970-1974 period. The conventional measure implies that per capita output in real terms in Switzerland has grown at the amual rate of 14.9 percent over this period while U.S. per capita output has grown at a 2.3 percent annual rate. Per capita output in

\footnotetext{
18Contrary to the pattern observed in Table IV, the conventional measture using the exchange rate is higher after 1970 than the PPP.based measure in most cases. However, as noted in footnote 16, there is no necessary reason for the conventional measure to fall on either side of the PPP-based measure. In this paper, there is no discussion of the factors producing this difference in pattern. It can be noted, however, that key factors explaining the difference are (a) a steady increase over the period in the number of convertible currencies; (b) varying degrees of intervention in the foreigrt exchange markets; (c) varying degrees of constraints on goods and capital movements; and (d) the changing role of the U.S. dollar as a reserve currency.
} 
Switzerland, in fact, has grown even slower than that of the United States over this period, at 2.1 percent per year compared to 2.3 percent. Such an anamolous result holds in general. Per capita output in Sweden, for example, has grown at the same rate as that for the United States over the same (1970-1974) period. The conventional measure, however, shows that per capita output in Sweden has increased substantially (close to 20 percent) relative to that for the United States.

Comparison of estimates derived from the more appropriate PPP-based measure does not support the claim that the U.S. lead in per capita output has been overtaken in the 1970s. For example, whereas the conventional measure for Sweden reached its high of 118 in 1975, the PPP-based measure was only 80 percent of U.S. per capita output. The conventional measure also placed Canada ahead of the United States in 1976; however, its PPP-based measure was below that of the United States, at 91 percent. As noted in Table V, PPP.based estimates of per capita output for Switzerland are not available. However, in view of the low growth rate of per capita output in Switzerland relative to the United States since as far back as 1960 (1.98 percent vs. 2.36 percent), when the U.S. lead was judged to have been substantial (see Table IV), it is not likely that Switzerland had overtaken the lead by 1976.

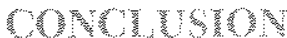

The allegation that the United States has been overtaken in its per capita output by a number of indus- trialized conntries in the $1970 \mathrm{~s}$ is based on an exchange rate-based measure which has been shown to be unreliable. When estimates of the more appropriate PPP-based measure are constructed, the allegation is not supported. That does not mean that one should be complacent about the performance of the U.S. economy. But it denies the factual basis for the claim that "[r] elative to achievements in the rest of the world, the U.S. economy no longer 'delivers the goods." "19

Although the United States has yet to lose its lead in per capita output, the estimates of PPP-based measures through 1976 indicate that the U.S. lead has indeed narrowed since 1950. One could cite many contributing factors to this development — such as the imperatives for reconstruction provided for some countries by the ravages of World War II, and the opportunities for adapting avallable production technologies. ${ }^{2}$ However, the fact that the U.S. lead has been narrowed does not necessarily mean that it is bound to be overtaken in the future. The future is not necessarily an extrapolation of past trends. The comparative levels of U.S. per capita output in the future will be determined solely by this country's relative success in harnessing opportunities for growth in per capita output.

\footnotetext{
19Thurow, "The Myth."

20See Edward F. Denison, "The Contribution of Capital to the Post-War Growth of Industrial Countries," in U.S. Economic Growth From 1976 to 1986: Prospects, Problems, and Patterns - Volume 3 Capital, Studies prepared for the use of the Joint Economic Committee, 94th Cong, 2nd Sess, Novenber $15,1976$.
}

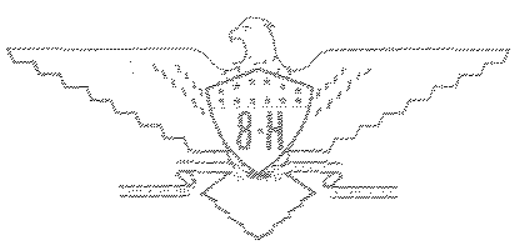

